\title{
Distinct Habits Of Sun Exposures Lead To Different Impacts On Some Facial Signs Of Chinese Men Of Different Ages
}

This article was published in the following Dove Press journal: Clinical, Cosmetic and Investigational Dermatology

\section{Frederic Flament ${ }^{\prime}$ \\ David Amar ${ }^{2}$ \\ Matthieu Forichon ${ }^{3}$ \\ Johanna Caron (1D) \\ Caroline Negre ${ }^{4}$}

'L'Oréal Research and Innovation, Clichy, France; ' ${ }^{2}$ 'Oréal Research and Innovation, Shanghai, People's Republic of China; ${ }^{3}$ Nous Avions Rendez-Vous, Lyon, France; ${ }^{4}$ L’Oréal, Levallois-Perret, France

Correspondence: Frederic Flament L'Oréal Research and Innovation, 9 Rue Pierre Dreyfus, Clichy 92110, France

Tel +33149795334

Fax +33149795142

Email frederic.flament@rd.loreal.com
Objective: To clinically evaluate the impacts of sun exposures on some facial signs of differently aged Chinese men with a distinct behavior vis à vis sun exposures.

Methods: Two comparable cohorts of Chinese men (aged 18-75 years old), living in two cities (Shanghai, Hong Kong) were created according to their usual behavior towards sun exposure and through their variable use(s) of a photo-protective product, i.e. non-sun-phobic $(\mathrm{N}=127)$ and sun-phobic $(\mathrm{N}=134)$. Standard photographs (full-face and $45^{\circ}$ lateral) allowed to focus on 13 facial signs that were further graded by 15 experts and dermatologists, using a referential Skin Aging Atlas. Absolute differences in the scores of each sign were used (non-sun-phobic minus sun-phobic), by age-classes, to better ascertain the impact of sun exposures and a photo-protecting product, when used.

Results: Most facial signs, particularly wrinkles and skin texture, differentiated the two cohorts. Some others showed some erratic changes with age, albeit more pronounced at older ages. In contrast with previous results obtained in Chinese women, the changes observed in men were not only of a lessened severity but were undetected at early ages ( $<30$ years old). Overall, these different behaviors with regard to sun exposures led to significant differences in the facial signs of Chinese men. The latter can be illustrated by two virtual morphings that combine the impacts of both intrinsic and extrinsic aging processes.

Conclusion: The present work illustrates, for the first time, some specificities of the impacts of sun exposures on the facial skin of Chinese men, more expressed at older ages, inversely to those observed in Chinese women, occurring at younger ages.

Keywords: facial aging, Asian men, solar exposures, photo-aging, skin aging atlas

\section{Introduction}

The various impacts of Sun/UV exposure(s) on the human skin are widely documented as they bring many cutaneous consequences of all kinds. These range from un-aesthetical disorders (wrinkling, ptosis, red-neck, dyschromia, etc.), sun-burn, photo-allergic/phototoxic reactions, up to highly serious diseases such as Basal Cell Carcinoma or Melanoma. $^{1-10}$ The progressive sun-induced changes brought to the clinical aspect of the skin represent the well-known photo-aging process that superimposes to the unavoidable chronological aging. More recent findings $s^{6,11-14}$ indicate that, in addition to impacts of various lifestyles (smoking, alcohol consumption, etc.), aerial pollution is another factor that boosts the facial skin aging process, in women, regardless of sun exposure habits. ${ }^{15}$ The various amplitudes and kinetics of sun-induced changes/damages are closely linked to: i) ethnicity (e.g. photo-types), ii) daily sun exposures (frequency, 
outdoor/indoor occupation). Both factors largely drive the individual skin response to the UVB/UVA assaults. However, a review of the literature reveals that a majority of studies have been conducted on fair skinned Caucasian subjects since less photo-protected (photo-types I and II). An extreme scenario is found on Australians of European ancestry (i.e. Keltic) who endure a high prevalence of Melanoma. The impacts of sun exposures on other ethnicities than Caucasians were explored by fewer studies. ${ }^{4,5,16-19}$

Inseparable to ethnicity, the cultural imprint differently drives humans with regard to their behavior vis à vis sun exposures, i.e. seeking or avoiding them. Paradoxically, the less photo-protected Caucasians are often sun-seekers whereas better photo-protected ethnicities (e.g. Africans, Arabians, Indians) daily avoid sun exposures through garments or veils. On such aspect, Asian subjects (Chinese, Japanese) represent an intermediate case study. At first, with regard to their constitutive skin complexion (photo-types II to IV). Second, Asian people are fully aware - by multi-centenarian texts - about the deleterious effect of sun exposures on their skin. These legendary texts even bear psycho-social impacts: in China, Japan or Korea, a pale skin complexion bears a higher social status. These comments greatly drove our group of research to enlarge the scope to different ethnicities (Chinese, Japanese), and genders $^{20,21}$ as most studies focused on women, major consumers of cosmetic products or aesthetical corrective actions. The present study was based on a similar protocol that was previously used on Japanese, Chinese and Caucasian women, of different sun habits: sun-phobic or non-sun-phobic. ${ }^{8,22}$ Here, the facial signs of 261 Chinese men of various ages, living in two Chinese cities (Shanghai, Hong Kong), with opposite behaviors vis à vis sun exposure and different use(s) of photo-protective products. All subjects were clinically graded by 15 trained experts from standardized, focused digital photographs, using a Skin Aging Atlas dedicated to Asian type (see below) as referential material. The results of this investigation are the objects of the present paper.

\section{Materials And Methods}

\section{Subjects}

Two hundred and sixty-one Chinese men, differently aged (18-75 years old), residing in the Shanghai $(\mathrm{N}=168)$ and Hong Kong $(\mathrm{N}=93)$ areas since more than 15 years, participated in the study. They were recruited through Chinese job agencies dedicated to part-time occupations. They were examined and enrolled by a local dermatologist, who initially asked if they were rather sun-phobic (SP) or non-sun-phobic (NSP). Apart from this decisive binary question, the absence of a particular skin disease/ disorder was checked. All men were classified as phototypes II to IV.

Inclusion criteria concerned the absence of any pathological skin disorder or affliction (severe acne, atopic skin, abnormal desquamation, etc.) and a permanent residence of more than 15 years in the considered city. Smokers or those entailed to a regular medication were excluded from the study. All subjects were informed about the purpose of the study, signed an informed consent and granted their rights to imaging.

Three types of clustering were therefore used (see below) following a previously published methodology. ${ }^{16}$ These led to create two cohorts balanced in age-classes and their opposite behavior with regard to sun exposure, as shown in Table 1.

\section{Clustering Procedure}

At first, to establish their usual relationships with sun exposures, subjects were asked to fill a questionnaire (Table 2) written in Chinese Mandarin \& Cantonese. The latter aimed at establishing a Sun History and Habits Index (SHHI) by

Table I Distribution Of Subjects By Age-Classes And Their Usual Attitude Versus Sun Exposures (Sun-Phobic, SP Or Not, NSP) Within The Two Cities

\begin{tabular}{|c|c|c|c|c|c|c|}
\hline Panels, Location/Age Clusters & Shanghai (SP) & Shanghai (NSP) & Hong Kong SP) & Hong Kong (NSP) & Total SP & Total NSP \\
\hline$\leq 30 y$ & 30 & 14 & 11 & 6 & 41 & 20 \\
\hline $31-40 y$ & 17 & 10 & 12 & 6 & 29 & 16 \\
\hline $4 I-50 y$ & 12 & 8 & 9 & 8 & 21 & 16 \\
\hline $5 I-60 y$ & 8 & 16 & 7 & 8 & 15 & 24 \\
\hline$>60 y$ & 19 & 34 & 9 & 17 & 28 & 51 \\
\hline \multirow[t]{2}{*}{ Total } & 86 & 82 & 48 & 45 & 134 & 127 \\
\hline & \multicolumn{2}{|l|}{168} & \multicolumn{2}{|l|}{93} & \multicolumn{2}{|l|}{261} \\
\hline
\end{tabular}


Table 2 The Questionnaire Filled By All Subjects Concerning Their Usual And Past Habits Vis À Vis Sun Exposures And Their Use(s) Of A Photo-Protective Product. In Bold, The Numbers Used For Calculating The SHHI

\begin{tabular}{|l|l|l|}
\hline $\begin{array}{l}\text { Have You Ever Spent More Than } \mathbf{4} \text { hrs A Day Outdoors For } \\
\text { Professional Or Recreational Activities }\end{array}$ & \\
\hline Between 0 and 7 years old ... & $\mathbf{I}-$ No & $\mathbf{2}$ - Occasionally \\
... with sun protection? & $\mathbf{I}-$ Yes & $\mathbf{2}-$ No \\
Between 7 and I8 years old ... & $\mathbf{I}-$ No & $\mathbf{2}-$ Occasionally \\
$\ldots$ with sun protection? & $\mathbf{I}-$ Yes & $\mathbf{2}-$ No \\
After I8 years old ... & $\mathbf{I}-$ No & $\mathbf{2}$ - Occasionally \\
$\ldots$ with sun protection? & $\mathbf{I}-$ Yes & $\mathbf{2}-$ No \\
At the present time ... & $\mathbf{I}-$ No & $\mathbf{2}$ - Occasionally \\
$\ldots$ with sun protection? & $\mathbf{I}-$ Yes & $\mathbf{2}-$ No \\
\hline
\end{tabular}

taking into account their daily sun exposures ( $>4 \mathrm{hrs}$ a day) and the regular use (or not) of a photo-protective cosmetic product. Then, this index is obtained by multiplying, in each age-class, the numbers $(1,2$ or 3 ) of the exposure by those ( 1 or 2 ) corresponding to the use of a photo-protective product. The global SHHI is obtained by adding all four indexes, further divided by 4 . Hence, this index varies from 1 to 6 , where 1 corresponds to the lowest degree of sun exposures $([1+1+1+1] /$ 4). Hence, $6([6+6+6+6] / 4)$ expresses the most extreme degree with a regular sun exposure since young ages, devoid of photoprotection. In such calculated index, 3 represents men who are regularly exposed to sun with a regular photo-protective habit, i.e. the intermediate case.

Second, the dermatologist was asked to observe each coded picture and to attribute a severity score (0-2) of texture (wrinkles and sagging) and dyschromia (0: low, 1: medium, 2: intense) for each third of the full-face (forehead and eyes/under the eyes, cheek, nose and upper lip/ mouth, jawlines and neck). An average score was calculated for the full-face by summing up all three scores. The three other averaged full-face gradings of skin wrinkled/ folded aspect, global lack of firmness and dyschromia were then added and averaged in all age-classes, leading to a global grading of facial photo-damages, thereby ranging $0-6$, where 6 represents the most extended photodamages either in wrinkles, sagging/ptosis or dyschromia.

Third, by merging and averaging the grades established by the dermatologist with the SHHI value, a final score is obtained on a $0-6$ scale, that combines clinical damages and sun exposures habits, the Global Score Sun Impact (GSSI). Hence, the “frontier" between SP and NSP subjects was arbitrarily set at 3 . The latter seems thus a reasonable compromise between clinical assessments and sun exposures habits for differentiating SP from NSP subjects.

\section{Protocol}

All subjects of each city visited on a single occasion our local facilities in Shanghai and Hong Kong at different timings in the morning, on two successive weeks (Monday to Friday, approx. 15 visits per day) in each city. Subjects were asked to visit with bare skin, clean shaved. Prior to photographic shootings, the faces of all subjects were gently cleaned by cotton pads soaked with an Ethanol/ Water solution $(70 / 30, \mathrm{v} / \mathrm{v})$ to eliminate sebum or sweat, sources of an undesired shine. All men rested for $15 \mathrm{mins}$ under ambient conditions (Temperature: $21 \pm 1^{\circ} \mathrm{C}$, Relative Humidity: $50 \pm 5 \%$ ), a timing used by subjects to fill the questionnaires.

\section{Pictures Acquisitions}

Subjects were photographed under standard conditions afforded by the Bench HeadScan (Orion Concept ${ }^{\mathrm{TM}}$, Tours, France), using a Nikon ${ }^{\mathrm{TM}}$ D300 digital camera fitted with a Nikon ${ }^{\mathrm{TM}} 105 \mathrm{~mm}$ lens (200 ISO sensitivity, 1/60 second exposure time, minimum aperture f/32). For each subject, a set of three photographs was obtained: one frontfull face and two others from $45^{\circ}$ left and right sides vis à vis the nose axis and all were asked to adopt the most neutral expression during the photographic shootings. Pictures were further blind-coded and used for further zooming/focusing on some facial signs of interest, i.e. apt at being graded by 15 trained experts and dermatologists, using specific scales of severity (see below).

In addition to standard photographic shootings, a magnifying imaging instrument Dermascore ${ }^{\circledR}$ (Monaderm ${ }^{\mathrm{TM}}$, Monaco) was used to image the homogeneity of facial pigmentation (cheeks), under crossed polarized light. This instrument allows to attribute different grades of severity $(0-5)$ of this skin feature. ${ }^{23,24}$ 


\section{Evaluation And Grading Of Facial Skin Aging Signs}

The panel of 15 experts graded the severity of all facial signs, using a referential material dedicated to Asian type, as part of a Skin Aging Atlas collection. ${ }^{10,25}$ These standard photographic Atlases comprise various scales of severity of some facial signs of Chinese men. As such, they offer a good reliability and robustness in clinical evaluations. ${ }^{20,21,25,26}$ Accordingly, a complete mapping of 13 facial signs was recorded according to their respective gradings, covering four major clinical domains: i) wrinkles and skin texture (6 signs), ii) pigmentation disorders (3 signs), iii) Sagginess/Ptosis (2 signs), iv) skin redness (1 sign) and v) cheek skin pores (1 sign). The choice of such rather high number of clinical signs aimed at adopting the widest "cross-section" of all possibly sun-impacted facial signs, i.e. a comparable approach to that used in the previous investigation of Chinese men or women enduring a severe aerial chronic urban pollution. ${ }^{13,21}$ The facial signs used here, as markers of skin aging, are illustrated in Table 3.

The panel of 15 experts and dermatologists assessed these 13 signs through all photographs that were resized and reframed under Standard Operational Procedure with editing software (Photoshop version $10^{\circledR}$ ). This step ensured that only one facial sign was displayed on the screen, with no impact on the overall facial appearance. All pictures were presented to each expert at random, to eliminate bias. To ensure the robustness of this process, several pictures were presented twice during the evaluation process. The latter was performed under standardized conditions of lighting, position (expert being seated $1 \mathrm{~m}$ from the screen) and calibration (24 inches, $1920 \times 1200$ pixel high-resolution screen calibrated with a colorimeter). The attributed grade of a given facial sign of each subject was, therefore, an averaged value ( \pm SEM, Standard Error of the Mean) calculated from the 15 experts' gradings.

\section{Global Synthesis Of Results On Major Clinical Clusters}

The three major facial clinical clusters - wrinkles \& skin texture (6 signs), pigmentation disorders (3 signs) and ptosis \& sagging (2 signs) - that appeared significantly affected by sun exposures, with different grading scales, were specifically analyzed by arithmetically transforming their respective scales $(0-5$ to $0-7)$ into a same $0-5$ scale.
Table 3 I3 Facial Signs Related To Asian Men As Described In Skin Aging Atlas Volume 2

\begin{tabular}{|c|c|c|}
\hline Facial Signs & $\begin{array}{l}\text { Definition Of Scored } \\
\text { Observation }\end{array}$ & Scale \\
\hline Forehead wrinkles & $\begin{array}{l}\text { Depth of the transverse wrinkles on } \\
\text { the forehead. }\end{array}$ & $0-7$ \\
\hline Inter-ocular wrinkles & $\begin{array}{l}\text { Depth of horizontal folds between } \\
\text { inner eye corners. }\end{array}$ & $0-7$ \\
\hline $\begin{array}{l}\text { Drooping of upper } \\
\text { outer eyelid }\end{array}$ & $\begin{array}{l}\text { Superior eyelid differently subsides } \\
\text { in its external part and covers upper } \\
\text { edge of eye. }\end{array}$ & $0-5$ \\
\hline $\begin{array}{l}\text { Periorbital wrinkles } \\
\text { (upper cheek area) }\end{array}$ & $\begin{array}{l}\text { Depth of folds at malar zone below } \\
\text { Crow's feet, eye orbit excepted. }\end{array}$ & $0-6$ \\
\hline Nasolabial fold & $\begin{array}{l}\text { Depth of the folds present on face } \\
\text { between the base of the nose and lips. }\end{array}$ & $0-7$ \\
\hline Marionette lines & Depth of folds at the corner of lips. & $0-7$ \\
\hline Chin withering & $\begin{array}{l}\text { Severity of cutaneous degradation } \\
\text { (irregularity, unevenness). }\end{array}$ & $0-5$ \\
\hline $\begin{array}{l}\text { Ptosis of the lower } \\
\text { part of the face }\end{array}$ & $\begin{array}{l}\text { Sagging severity of the lower parts } \\
\text { of the chin. }\end{array}$ & $0-5$ \\
\hline $\begin{array}{l}\text { Density of } \\
\text { pigmentary spots }\end{array}$ & $\begin{array}{l}\text { Number of spots per area unit on the } \\
\text { cheek area according to grades of atlas. }\end{array}$ & $0-5$ \\
\hline $\begin{array}{l}\text { Localized pigmentary } \\
\text { spots of the cheek }\end{array}$ & Number of spots, contrast and size. & $0-7$ \\
\hline $\begin{array}{l}\text { Pigmentary } \\
\text { homogeneity } \\
\left(\text { DermaScore }^{\circledR}\right)\end{array}$ & Size and contrast of spots on cheek. & $0-5$ \\
\hline Vascular disorders & $\begin{array}{l}\text { Diffused redness and microvessels } \\
\text { visible on the face and especially cheeks. }\end{array}$ & $0-5$ \\
\hline Cheek skin pores & $\begin{array}{l}\text { Size of visible pores on the cheek } \\
\text { irrespective of their densities. }\end{array}$ & $0-5$ \\
\hline
\end{tabular}

An average score on all considered signs, gathered within a facial clinical cluster, was then calculated.

\section{Statistics}

The gradings of all facial signs in the two cohorts of subjects (SP vs NSP) were paired compared, in each ageclass, using a Student's $t$-Test, taking $\mathrm{p}<0.05$ as a significant threshold for independent samples. To assess the impact of age in both groups (SP and NSP) on the four major clinical signs (wrinkles/skin texture, pigmentation, vascular disorders, sagging): a 2 factor ANOVA (experts and age cluster) was performed, using a 2 factor variance analysis (ANOVA), combined with a Newman-Keuls test 
to detect significant differences between age-classes. All calculations were performed through the SPSS statistical package (SPSS/IBM, Chicago/ILL, USA).

\section{Virtual Morphing}

By compiling the average grades obtained at different ages for NSP \& SP groups and previous data on environmental impacts, ${ }^{20,21}$ two virtual morphings of two Chinese men (SP and NSP) can be created. Gathering all relevant signs, these morphings help to illustrate the progressive changes in the facial appearance along the life span and their respective differences related to their habits towards sun exposures.

\section{Results}

\section{Facial Signs}

Table 4 gathers the differences in grading scores (expressed as NSP minus SP) obtained in the 5 ageclasses. In bold, differences indicate a significant increased severity of the concerned facial signs with sun exposures.

For the sake of clarity, only differences above 0.2 score units are taken into consideration. Table 4 shows that forehead wrinkles are most affected in NSP subjects, as compared to SP subjects. This is globally more evident at ages beyond 40 years old. Some other structural signs show erratic fluctuations (periorbital wrinkles, nasolabial folds, chin withering, cheek skin pores). Marionette lines seem however more pronounced among NSP subjects at ages above 50 years old. The case of pigmentary or vascular disorders is intriguing as most show very erratic (increased or decreased) changes within age-classes.
Vascular disorders are more difficult to assess as subjected to biases (emotional stress, heat, etc.). All these observed erratic changes with age should, however, be analyzed with caution: the sub-grouping of subjects with age-classes and sun exposures, inevitably leads to cohorts of too low sizes to being statistically paired-compared with confidence, i.e. 16 NSP vs 21 SP or 22 vs 15 (Table 1).

However, when regrouping facial signs under four large clinical clusters (wrinkles and skin texture, pigmentary disorders, sagging and vascular disorders), all being arithmetically transformed into the same 0-5 scale, results appear more explicit. Figure 1 shows that wrinkles and skin texture (6 signs) only differentiate the two cohorts at ages above 40 years old, where the NSP subjects show increased grades, as compared to SP subjects. At the exception of two age-classes ( $\leq 30$ years old and $41-50$ years old), the 3 regrouped facial pigmentary disorders appear significantly higher in the NSP subjects as compared to those of SP subjects (Figure 2). With regard to the two regrouped signs of facial sagging, the two cohorts only significantly differentiate at ages $>60$ years old (Figure 3). Vascular disorders (Figure 4) confirm the impact of sun exposures as they differentiate the two cohorts in three age-classes (31-40, 51-60 and $>60$ years old). Of note, in many cases (Wrinkles/Texture excepted), the 41-50 years' age-class shows slight differences found nonsignificant (see Discussion part). Of note, no significant changes in the four major clusters of facial signs were found in the younger group ( $<30$ years old $)$.

Table 4 Clinical Solar Exposures Impact In Asian Men. In Bold A Significantly More Severe Score In The Non-Sun-Phobic Cohort (NSP) Versus The Sun-Phobic Cohort (SP). In Italic A Significantly Less Severe Clinical Score In NSP Cohort Versus SP Cohort

\begin{tabular}{|c|c|c|c|c|c|}
\hline Facial Signs & $\leq 30$ y $\Delta$ (NSP-SP) & $31-40$ y $\Delta$ (NSP-SP) & $4 I-50$ y $\Delta$ (NSP-SP) & $5 \mathrm{I}-60$ y $\Delta$ (NSP-SP) & $>60$ y $\Delta$ (NSP-SP) \\
\hline Forehead wrinkles & 0.08 NS $(p=0.59)$ & -0.08 NS $(p=0.54)$ & $0.89 \mathrm{~S}(\mathrm{p}<0.0001)$ & $0.79 \mathrm{~S}(\mathrm{p}<0.005)$ & $1.04 \mathrm{~S}(\mathrm{p}<0.000 \mathrm{I})$ \\
\hline Inter-ocular wrinkles & $-0.04 \mathrm{NS}(p=0.63)$ & $0.01 \mathrm{NS}(p=0.96)$ & $0.58 \mathrm{~S}(\mathrm{p}<0.000 \mathrm{I})$ & $0.33 \mathrm{~S}(\mathrm{p}<0.05)$ & 0.08 NS $(p=0.45)$ \\
\hline Periorbital wrinkles & $0.16 \mathrm{~S}(\mathrm{p}<0.005)$ & $0.18 \mathrm{~S}(\mathrm{p}<0.05)$ & $0.31 \mathrm{~S}(p<0.005)$ & $0.03 \mathrm{NS}(\mathrm{p}=0.78)$ & $0.19 \mathrm{~S}(\mathrm{p}<0.05)$ \\
\hline Nasolabial fold & $0.19 \mathrm{~S}(\mathrm{p}<0.0001)$ & $0.09 \mathrm{NS}(\mathrm{p}=0.09)$ & $0.52 \mathrm{~S}(\mathrm{p}<0.000 \mathrm{I})$ & -0.15 NS $(p=0.38)$ & $-0.28 S(p<0.05)$ \\
\hline Marionette lines & 0.01 NS $(p=0.95)$ & $-0.44 S(p<0.005)$ & 0.05 NS $(p=0.68)$ & $0.49 \mathrm{~S}(\mathrm{p}<0.05)$ & $0.62 \mathrm{~S}(\mathrm{p}<0.05)$ \\
\hline Chin withering & $0.05 \mathrm{NS}(\mathrm{p}=0.58)$ & $-0.18 S(p<0.05)$ & $0.63 \mathrm{~S}(\mathrm{p}<0.0001)$ & 0.04 NS $(p=0.75)$ & 0.08 NS $(p=0.23)$ \\
\hline Density of pigmentary spots & -0.04 NS $(p=0.7 I)$ & $0.05 \mathrm{NS}(p=0.67)$ & $0.53 \mathrm{~S}(\mathrm{p}<0.01)$ & $0.15 \mathrm{NS}(\mathrm{p}=0.58)$ & $0.60 \mathrm{~S}(\mathrm{p}<0.005)$ \\
\hline Localized pigmentary spots & $-0.4 I S(p<0.005)$ & $0.69 \mathrm{~S}(\mathrm{p}<0.0001$ & $-1.05 S(p<0.0001)$ & $1.63 \mathrm{~S}(p<0.0001$ & 0.05 NS $(p=0.64)$ \\
\hline Pigmentary homogeneity & 0.03 NS $(p=0.62)$ & $0.53 \mathrm{~S}(\mathrm{p}<0.000 \mathrm{I})$ & $-0.43 S(p<0.0001)$ & $0.46 \mathrm{~S}(\mathrm{p}<0.000 \mathrm{I})$ & $0.28 S(p<0.005)$ \\
\hline Ptosis of the lower part of face & -0.05 NS $(p=0.63)$ & -0.07 NS $(p=0.46)$ & 0.19 NS $(p=0.11)$ & -0.08 NS $(p=0.67)$ & $0.40 \mathrm{~S}(\mathrm{p}<0.05)$ \\
\hline Drooping of upper outer eyelid & $0.17 \mathrm{~S}(\mathrm{p}<0.0001)$ & 0.02 NS $(p=0.7 I)$ & 0.08 NS $(p=0.27)$ & $0.23 \mathrm{~S}(\mathrm{p}<0.05)$ & 0.06 NS $(p=0.37)$ \\
\hline Vascular disorders & 0.02 NS $(p=0.65)$ & $0.25 \mathrm{~S}(\mathrm{p}<0.000 \mathrm{I})$ & $-0.06 \mathrm{NS}(\mathrm{p}=0.43)$ & $0.39 \mathrm{~S}(\mathrm{p}<0.000 \mathrm{I})$ & $0.31 \mathrm{~S}(\mathrm{p}<0.0001)$ \\
\hline Cheek skin pores & $-0.33 S(p<0.005)$ & -0.17 NS $(p=0.20)$ & $0.50 \mathrm{~S}(p<0.005)$ & $-0.54 \mathrm{~S}(\mathrm{p}<0.000 \mathrm{I})$ & 0.14 NS $(p=0.16)$ \\
\hline
\end{tabular}




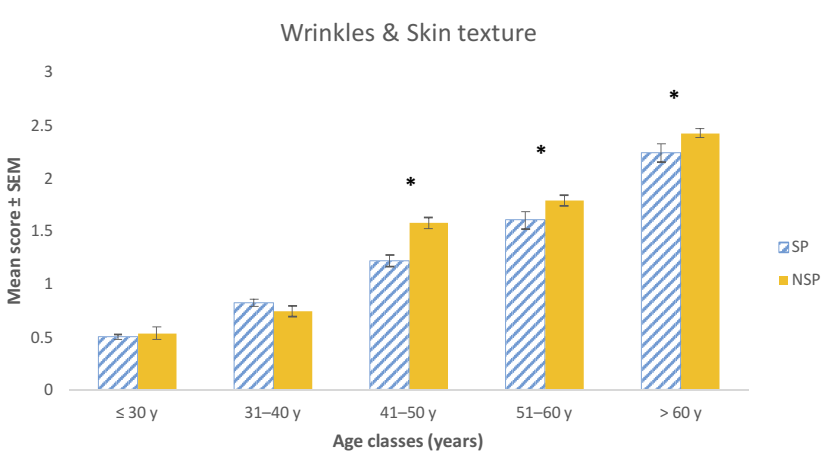

Figure I Changes, with age, in the grades of all 6-regrouped signs (mean \pm SEM) of the facial skin texture/wrinkling between NSP and SP Asian men. *Significant at a $\mathrm{P}<0.05$.

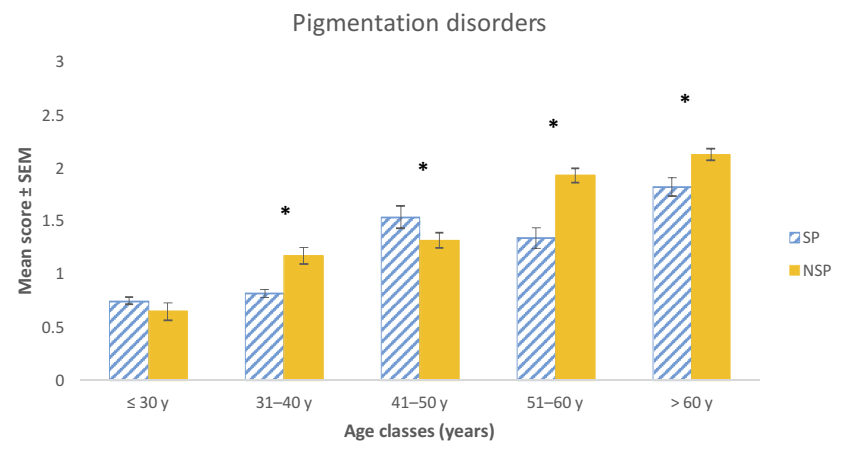

Figure 2 Changes, with age, in the grades of all 3-regrouped signs (mean \pm SEM) of the facial skin pigmentation between NSP and SP Asian men. *Significant at a $\mathrm{P}<0.05$.

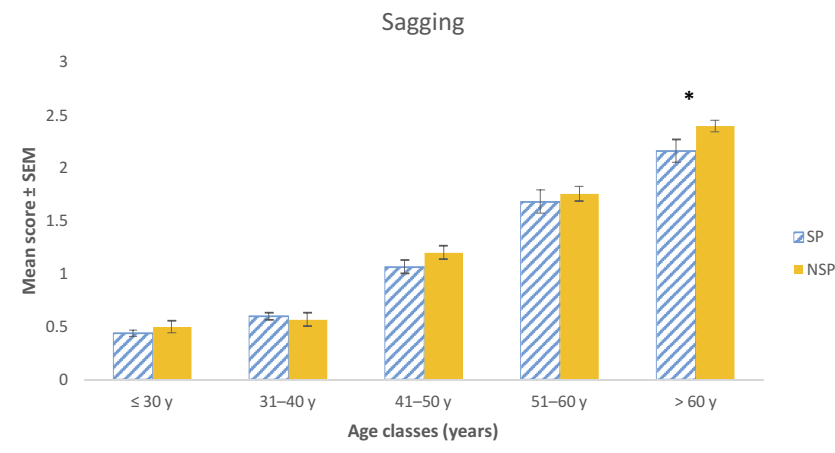

Figure 3 Changes, with age, in the grades of all 2-regrouped signs (mean $\pm \mathrm{SEM}$ ) of the facial skin sagging between NSP and SP Asian men. *Significant at a $p<0.05$.

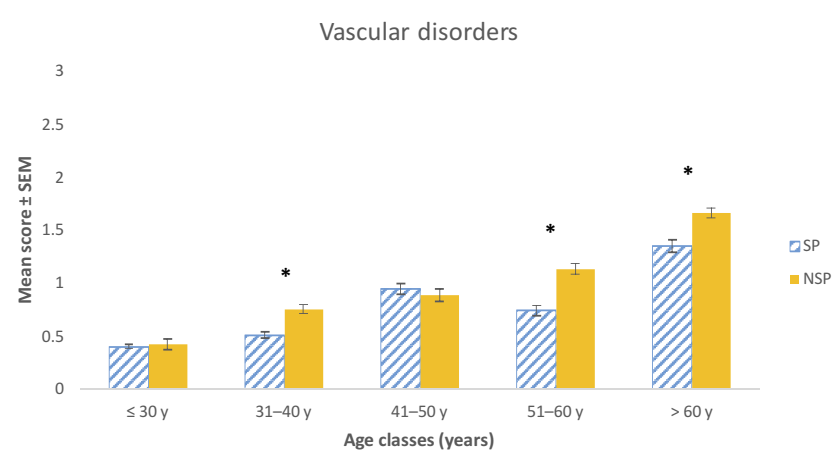

Figure 4 Changes, with age, in the grades of facial skin vascular disorders (mean \pm SEM) between NSP and SP Asian men. *Significant at a $\mathrm{p}<0.05$.

\section{Answers From The Questionnaire}

Self-declared habits of sun exposures are naturally imprecise, best viewed as estimates. Despite, the two cohorts significantly differentiate $(\mathrm{p}<0.05)$ in their average habits of sun exposures. The latter were about twice in NSP than SP subjects in their childhood and puberty periods $(<20$ years old) and of about four times past 30 years old. Photo-protective products were found more frequently used by SP subjects than the NSP cohort $(\approx+50 \%)$, although the difference was non-significant $(\mathrm{p}=0.1)$.

\section{Morphing}

All clinical grades were combined to previous data obtained for chronological aging ${ }^{20}$ or chronic aerial pollution impact ${ }^{21}$ and input, by 5 centered age-classes $(25,35,45,55$ and 65 years old), on a virtual simulation of SP or NSP Chinese man. These simulations (Figure 5) better illustrate the combined impacts of chronological aging and those resulting from different environments, including sun exposure habits, of Chinese men. It is worth mentioning that the morphing obtained from the SP cohort can hardly result from the sole chronological aging, as a total absence of sun exposure is obviously unrealistic.

\section{Discussion}

The present work completes our previous Asian studies on Chinese or Japanese SP or NSP women, ${ }^{16,22}$ using a comparable framework/protocol. In these previously studied women, the different sun exposure habits led to similar results, although of slightly more pronounced severities than those observed here on Chinese men. The present work indeed confirms and illustrates the impacts of more frequent sun exposures on the global facial aging of Chinese men, in agreement with previous works carried out on Asian subjects. ${ }^{5,6,16,19,26}$ However, the impacts of sun exposure(s) in Chinese men led to some erratic changes with age (vascular or pigmentary disorders), particularly in the $41-50$ years' class.

Such divergence with other age-classes is of a difficult interpretation. It may well result from a rather low number of paired comparisons and/or a strong influence of different individual specificities, i.e. different constitutive biological responses. These may account for the paradoxical result in pigmentary or vascular disorders where the SP cohort shows higher grades than the NSP cohort. Unsurprisingly, most signs appear more significantly aggravated in the two older groups, likely more superimposed to the chronological aging process. Interestingly, the facial signs of younger Chinese men $(<30$ 


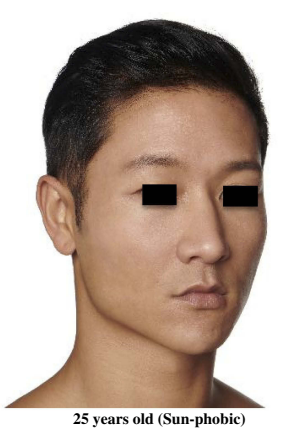

25 years old (Sun-phobic)
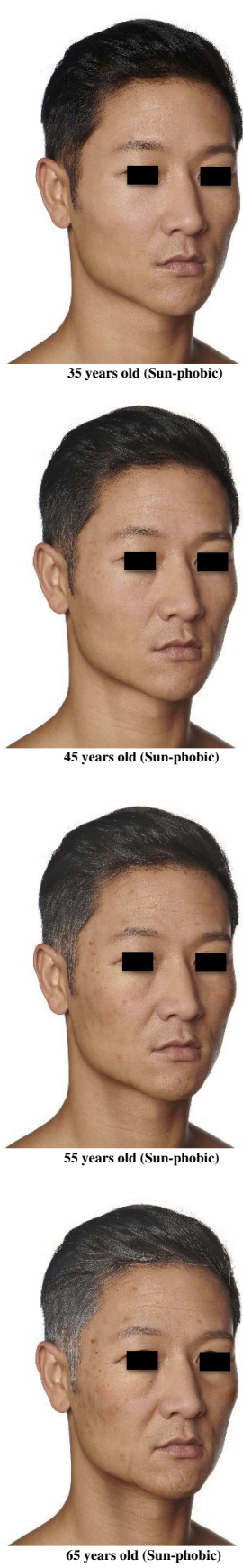

Figure 5 Simulations of the age-related changes in the facial appearance of a nonsun-phobic (NSP) or sun-phobic (SP) virtual Chinese man. years old) do not show significant changes according to their sun exposure habits. This finding much contrasts with data obtained on young Chinese women (20-29 years old) where changes in most facial signs are of an early onset, making them perceived much older by a panel of naïve observers, by about 6 years. ${ }^{22}$ Such gap is viewed as a significant biomarker of aging. ${ }^{27}$ Interestingly stronger impacts of chronic aerial pollution in young Chinese men were previously observed, as compared to Chinese women of same age. ${ }^{21}$

Although an aerial chronic urban pollution aggravates the signs of facial aging, as previously published, ${ }^{13,21}$ this factor was not considered for two major reasons. At first, the rather small sizes of the two cohorts (and their possibly different lifestyles) impede clear-cut conclusions. Second, the average air quality indexes (AQI) of these two Chinese cities do not much differ along a full year: Shanghai: $80-140$, Hong Kong 68-120 (source: www.numbeo.com), i.e. values classified from moderate to unhealthy for sensitive persons. The impact of an aerial urban pollution on skin aging was indeed more easily evidence ${ }^{13,21}$ by comparing men and women living in two very differently polluted Chinese cities, namely Baoding (AQI: 100-500) and Dalian (AQI: 50-100).

The present work sheds, we believe, a complementary light to the global impacts of sun exposures upon some facial signs of Chinese men still unexplored, up to our knowledge. It is hoped that the present study contributes to a deepened knowledge of the influence of various elements that alter the facial signs of aging, referred to as the generic term "exposome". ${ }^{14}$ The latter is in fact an intricate mosaic of environmental influences (sun exposures, aerial pollution), lifestyles (food, beverage, indoor aerial environment, smoking, use of protective cosmetic products, etc.). The fact that both genders differently respond to comparable environmental conditions is certainly not a new finding. At first, a different hormonal status (i.e. androgens vs estrogens) and its numerous influences on skin renewal, epidermal differentiation, different vascularization network, dermal thickness ${ }^{28-30}$ etc. are paramount factors the respective influences of which can hardly be addressed by the present work.

As an example, sun-exposed Korean men are more prone at developing hyperkeratosis than Korean women. ${ }^{5,31,32}$ Second, men and women generally differ with regard to their intimate relation with their skin. Women certainly take a greater care about their own appearance than men, worldwide, and Asian subjects make no exception. The different uses of cosmetic products between genders (an approx. 90/10 ratio) "speak by itself". In addition, moods (smile, anxiety, etc.) are likely differently expressed according to gender: on long term 
these expression wrinkles may be favored (or amplified with age) among women. ${ }^{33,34}$

However, our internal records (unpublished) indicate that Asian men (Chinese, Japanese, Korean) seem increasingly taking a greater care of their skin, sometimes by "borrowing" some skin care products of their wives or girl-friends, although these products may not perfectly suit with their specific needs. Whatsoever, these records suggest a better awareness of Asian men about factors that progressively alter their facial appearance, making them keener at alleviating their impacts.

It remains nevertheless clear that the different intimate relations with skin or facial appearance between both genders still own some psycho-social injustices: whereas wrinkles in women are negatively perceived and a source of anxiety, these are viewed as signs of maturity (or wisdom) in men. To summarize, the multifactorial notion of "exposome", not solely restricted to environmental factors, is probably more complex. It is likely modulated by powerful individual psychological factors, i.e. the different individual relations with sun exposure, food, alcohol, cosmetic products, self-image, survey of body weight, etc., all being much gender driven.

\section{Acknowledgments}

The authors want to thank Mr Didier Saint-Leger, Mrs Aurelie Abric, Mrs Aude Charbonneau, Mr Andrew Steel, Mrs Huixia Qiu, Mrs Sharon Shen, Mrs Agnes Hou, Mr Stephane Mathon, Mr Thierry Lageat, Mr Yann Andrea, Mrs Alice Laurent-Lesaffre and Mr Chengda Ye not only for their great help in completion of this paper and global study but also for their strong support and enthusiasm. The present work was entirely funded by the L'Oréal Research \& Innovation Department.

\section{Disclosure}

The authors report no conflicts of interest in this work.

\section{References}

1. Gilchrest BA. Skin aging and photo aging: an overview. $J$ Am Acad Dermatol. 1989;21:610-613. doi:10.1016/S0190-9622(89)70227-9

2. Zhao P, Zhu X, Liu Y, Wang B, Wang C, Burns FJ. Solar ultraviolet radiation and skin damage: an epidemiological study among a Chinese population. Arch Environ Health. 1998;53:405-409. doi:10.1080/ 00039899809605728

3. Eun HC. Cutaneous photodamage in Asians. $J$ Dermatol. 2001;28:614-616. doi:10.1111/jde.2001.28.issue-11

4. Chung JH. Photoaging in Asians. Photodermatol Photoimmunol Photomed. 2003;19:109-121. doi:10.1034/j.1600-0781.2003.00027.x

5. Chung JH, Lee SH, Youn CS, et al. Cutaneous photodamage in Koreans: influence of sex, sun exposure, smoking and skin color. Arch Dermatol. 2001;137:1043-1051.
6. Akiba S, Shinkura R, Miyamoto K, Hillebrand G, Yamaguchi N, Ichihashi M. Influence of chronic UV-exposure and lifestyle on facial skin photoaging - results from a pilot study. J Epidemiol. 1999;9(6 Suppl):S136-142. doi:10.2188/jea.9.6sup_136

7. Nouveau-Richard S, Yang Z, Mac-Mary S, et al. Skin ageing: a comparison between Chinese and European populations: a pilot study. $J$ Dermatol Sci. 2005;40:187-193. doi:10.1016/j.jdermsci.2005.06.006

8. Flament F, Bazin R, Laquieze S, Rubert V, Simonpietri E, Piot B. Effect of the sun on visible clinical signs of aging in Caucasian skin. Clin Cosmet Investig Dermatol. 2013;6:221-232. doi:10.2147/CCID. S44686

9. Sabziparvar AA, Shine KP, Forster PM. A model-derived global climatology of UV irradiation at the Earth's surface. Photochem Photobiol. 1999;69(2):193-202. doi:10.1111/j.1751-1097.1999.tb032 73.x

10. Flament F, Bazin R, Qiu H. Skin Aging Atlas. Volume 5, Photo-Aging Face \& Body. Paris: Editions Med'Com; 2017.

11. Kim EJ, Han JY, Lee HK, et al. Effect of the regional environment on the skin properties and the early wrinkles in young Chinese women. Skin Res Technol. 2014;20(4):498-502. doi:10.1111/srt.12144

12. Zhang Y, Jiang R, Kezele I, et al. A new procedure, free from human assessment, that automatically grades some facial skin structural sign in men of three ethnicities. Recording facial changes induced by a severe aerial pollution. Int J Cosmet Sci. 2019. [In press].

13. Flament F, Bourokba N, Nouveau S, Li A, Charbonneau A. A severe chronic outdoor urban pollution alters some facial aging signs in Chinese women. A tale of two cities. Int $J$ Cosmet Sci. 2018;40:467-481. doi:10.1111/ics.12487

14. Krutmann J, Bouloc A, Sore G, Bernard BA, Passeron T. The skin aging exposome. J Derm Sci. 2017;85:152-161. doi:10.1016/j. jdermsci.2016.09.015

15. Mayes AE, Murray PG, Gunn DA, et al. Environmental and lifetime factors associated with perceived facial age in Chinese women. PLoS One. 2010;5:215-270. doi:10.1371/journal.pone.0015270

16. Flament F, Velleman D, Yamamoto S, et al. Clinical impacts of sun exposures on the faces and hands of Japanese women of different ages. Int J Cosmet Sci. 2019;41:425-436. doi:10.1111/ics.v41.5

17. Tsukahara K, Sugata K, Ohushi A, et al. Comparison of age-related changes in facial wrinkles and sagging in the skin of Japanese, Chinese and Thai women. J Dermatol Sci. 2007;47:19-28. doi:10.1016/j.jdermsci.2007.03.007

18. Goh SH. The treatment of visible signs of senescence: the Asian experience. Br J Dermatol. 1990;122(Suppl 35):105-109. doi:10.111 1/j.1365-2133.1990.tb16134.x

19. Chung JH. The effects of sunlight on the skin of Asians. In: P.U. Giacomoni, editor. Sun Protection in Man. Elsevier Science B.V; 2001:69-90.

20. Flament F, Amar D, Feltin C, Bazin R. Evaluating age-related changes of some facial signs among men of four different ethnic groups. Int $J$ Cosmet Sci. 2018;40:502-515. doi:10.1111/ics.2018.40.issue-5

21. Flament F, Ye C, Amar D. Assessing the impact of an urban aerial pollution (UAP) on some facial signs of Chinese men of different ages. Int J Cosmet Sci. 2019;41:450-461. doi:10.1111/ics. 12558

22. Flament F, Bazin R, Qiu H, et al. Solar exposure(s) and facial clinical signs of aging in Chinese women: impacts upon age perception. Clin Cosmet Investig Dermatol. 2015;8:75-84. doi:10.2147/CCID.S72244

23. François G, Maudet A, McDaniel D, Giron F, Bazin R. Quantification of facial pores using image analysis. Cosm Dermatol. 2009;22(9):457-463.

24. Flament F, François G, Qiu H, et al. Facial skin pores: a multi-ethnic study. Clin Cosmet Invest Dermatol. 2015;8:85-93. doi:10.2147/CCID

25. Bazin R, Flament F. Skin Aging Atlas. Volume 2, Asian Type. Paris: Editions Med'Com; 2010.

26. Chien AL, Qi J, Grandhi R, et al. Effect of age, gender, and sun exposure on ethnic skin photoaging: evidence gathered using a new photonumeric scale. J Nat Medl Assoc. 2018;110(2):176-182. doi:10.1016/j.jnma.2017.05.001 
27. Christensen K, Thingaard M, Mc Gue M, Rexbye H, Hjelmborg JVB. Perceived age as a clinically useful bio-marker of ageing: cohort study. Br Med J. 2009;10(339):b5262. doi:10.1136/bmj.b5262

28. Lephart ED. A review of the role of estrogens in dermal aging and facial attractiveness in women. J Cosmet Dermatol. 2018;17:282288. doi:10.1111/jocd.12508

29. Golan R, Scovell JM, Ranasamy R. Age-related testosterone decline is due to waning of both testicular and hypothalamic pituitary function. Aging Male. 2015;15:201-204. doi:10.3109/13685538.2015.1052392

30. Lephart D. Skin aging and oxidative stress: equal's anti-aging effects via biochemical and molecular mechanisms. Ageing Res Rev. 2016;31:36-54. doi:10.1016/j.arr.2016.08.001
31. Kwon OS, Hwang EJ, Bae JH, et al. Seborrheic keratosis in the Korean males: causative role of sunlight. Photodermatol Photoimmunol Photomed. 2003;19(2):73-80. doi:10.1034/j.1600-0781.2003.00025.x

32. Song EJ, Lee JA, Park JJ, et al. A study on seasonal variation of skin parameters in Korean males. Int. J. Cosmet Sci. 2015;37:92-97. doi:10.1111/ics.2015.37.issue-1

33. McDuff M, Kodra E, Kaliouby RE, LaFrance M. A large scale analysis of sex difference in facial expressions. PLoS One. 2017;12 (4):e0173942. (doi.org/10.1371). doi:10.1371/journal.pone.0173942

34. Hillebrand GG. Facial wrinkling: the marquee clinical of aging skin. In: Farage MA, Miller KW, Maibach HI, editors. Textbook of Aging Skin. Berlin, Heidelberg: Springer-Verlag; 2010:911-918.

\section{Publish your work in this journal}

Clinical, Cosmetic and Investigational Dermatology is an international, peer-reviewed, open access, online journal that focuses on the latest clinical and experimental research in all aspects of skin disease and cosmetic interventions. This journal is indexed on CAS
The manuscript management system is completely online and includes a very quick and fair peer-review system, which is all easy to use. Visit http://www.dovepress.com/testimonials.php to read real quotes from published authors. 